\title{
www.fmhjob.ch - le portail de l'emploi pour les médecins \& le personnel médical
}
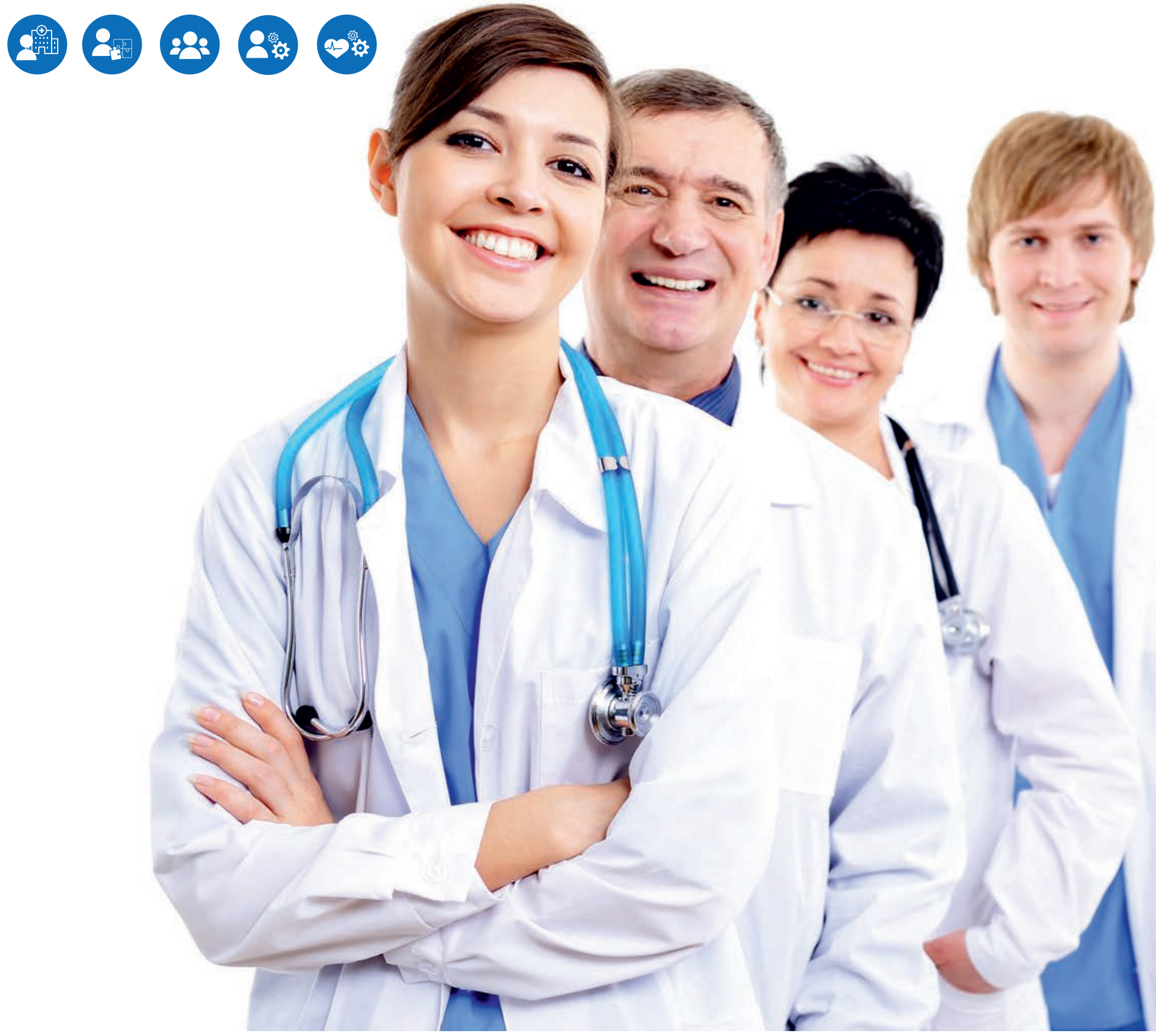

Proposer un emploi

- Saisie, mutation et gestion simples des annonces

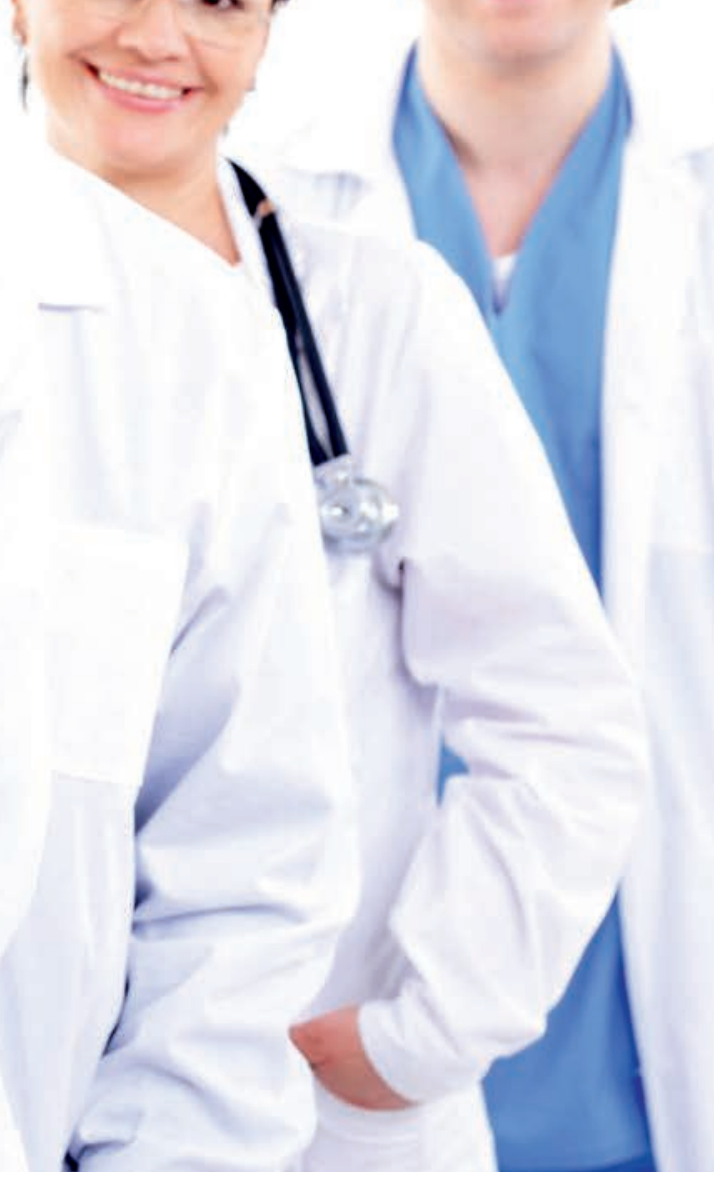

T. FMH SERVICES

- Optimisation des coûts grâce à la publication combinée web (www.fmhjob.ch) - impression (Bulletin des médecins suisses)

- Offre chiffrée

- Consultation des demandes d'emploi (abonnement)

\section{Rechercher un emploi}

- Saisie, mutation et gestion simples et gratuites des demandes d'emploi

- Publication gratuite sur web (www.fmhjob.ch) ainsi que tarif préférentiel pour la publication dans le Bulletin des médecins suisses

- Saisie et gestion des candidatures en ligne

- Nouvelles offres d'emploi gratuites par e-mail (Job Mailer)

CONSULTING

\section{FMH Consulting Services AG}

Avenue d'Ouchy 66, 1006 Lausanne

Tél. 0219224435

mail@fmhconsulting.ch - www.fmhservices.ch 